\title{
Thrombocytopenia in an Infant
}

\author{
Padmasani Venkat Ramanan - T. S. Arun Prasath • \\ Thanasegarapandian Kishore
}

Received: 18 March 2012 / Accepted: 5 July 2012 / Published online: 4 August 2012

(C) Dr. K C Chaudhuri Foundation 2012

A 87-d-old boy was brought for vaccination. He was second child of non-consanguineous parents. He was exclusively breast fed and thriving well. The child had received birth immunization and DTaP / HiB / IPV combination vaccine (1), OPV and HepB (2) at 6 wk.

On examination, the child was playful. Petechial spots were noted over the face and limbs. Otherwise general and systemic examination was normal.

Platelet count was $15000 / \mathrm{cu} \mathrm{mm}$. Hemoglobin was $10.4 \mathrm{~g} / \mathrm{dl}$, total leucocyte count-13070/cu mm and differential count:P-23.5,L-72.3, M-3.2, E -0.9, B-0.1. Coagulation profile, LFT, RFT and TORCH titres were normal. Peripheral smear showed normal RBCs, lymphocytosis and marked thrombocytopenia (hence no comment on platelet morphology). Mother's platelet count was 2.4 lakhs. HIV status was negative. Bone marrow aspiration showed normal megakaryopoeisis. A diagnosis of acute immune thrombocytopenic purpura (ITP) was made.

Intra venous immunoglobulin was given $1 \mathrm{~g} / \mathrm{kg}$ body weight. Platelet count after $24 \mathrm{~h}$ was $75000 /$ cumm. Repeat peripheral smear showed normal platelet morphology. The child was discharged without steroids. The platelet count was 5.4 lakhs after one wk and 2.7 lakhs after $4 \mathrm{wk}$. The child has received subsequent doses of vaccines and remains well.

ITP is typically a disease of 2-4 y old children [1]. Hashemi A et al, in a study of 72 cases of thrombocytopenia in children below 2 y found that $66 \%$ had ITP, 2 had
Wiskott Aldrich syndrome and 4 had Fanconi anemia [2]. Ramyar A and Kalanthari $\mathrm{N}$ retrospectively reviewed the chart of 202 pediatric patients with ITP. Of these, 96 were 24 mo of age or younger [3].

ITP should be considered in the differential diagnosis of thrombocytopenia even in infants. The principles of management are same as that for older children. Live viral vaccines should be administered after 3 mo of IVIG administration [4].

Acknowledgments The authors would like to thank Dr. Sumati Manjunath, Consultant, Pediatrics, a private practioner, who promptly identified thrombocytopenia and referred the child and Dr. Krishnaratnam, Hemato Oncologist, who was consulted during case management.

\section{References}

1. Scott JP, Montgomery RR. Idiopathic thrombocytopenic purpura. In: Kleigman, Behrman, Jenson, Stanton eds. $19^{\text {th }}$ ed. Kliegman: Nelson Textbook of Pediatrics. Philadelphia, USA: Elsevier; 2011.

2. Hashemi A, Kargar F Souzani A, Hazar N . Acute immune thrombocytopenic purpura in infants. Iranian J Pediatr Hematol Oncol. 2011;1:104-8.

3. Ramyar A, Kalantari N. Clinical features and treatment response of immune thrombocytopenic purpura in infants. Acta Medica Iranica. 2007;45:510-2.

4. IAP Committee on Immunization. Immunization in special situation. IAP guide book on immunization, Mumbai: Print Throb Creation; 2011. pp. 151.
P. Venkat Ramanan $(\bowtie) \cdot$ T. S. A. Prasath · T. Kishore Department of Pediatrics, Sri Ramachandra Medical College, Porur, Chennai, Tamil Nadu, India e-mail: padmasani2001@yahoo.com 